\title{
Equine protease inhibitor system as a marker for the diagnosis of chronic obstructive pulmonary disease (COPD)
}

\author{
Myriam E. Vinocur* ${ }^{1}$, Karin E. Brass ${ }^{1}$, Alexandre R. Caetano ${ }^{2}$, Letícia F. Silva ${ }^{1}$, Aline C. Silva ${ }^{1}$ \\ and Carlos A.M. Silva ${ }^{1}$ \\ ${ }^{1}$ Universidade Federal de Santa Maria, Centro de Ciências Rurais, Departamento de Clínica \\ de Grandes Animais, Laboratório de Imunogenética, Santa Maria, RS, Brazil. \\ ${ }^{2}$ Embrapa Recursos Genéticos e Biotecnologia, Parque Estação Biológica, Brasília, DF, Brazil.
}

\begin{abstract}
The protease inhibitor system (PI) was investigated to ascertain if it can be used as a marker of chronic obstructive pulmonary disease (COPD) in thoroughbred horses. Serum samples were taken from healthy thoroughbreds $(n=13)$ and those diagnosed as having COPD $(n=24)$ or inflammatory airway disease $(I A D, n=38)$ as well as from 3,600 undiagnosed thoroughbred horses. PI allelic and genotypic frequencies were estimated using protein electrophoresis on starch and polyacrylamide gels. The four groups of horses showed high genotypic similarity and none of the observed alleles or genotypes of the equine PI system were found to be associated with COPD.
\end{abstract}

Key words: horse, chronic obstructive pulmonary disease, protease inhibitor system.

Received: June 4, 2004; Accepted: March 31, 2005.

Chronic obstructive pulmonary disease (COPD - also known as chronic pulmonary disease, chronic small airway disease and chronic bronchitis/bronchiolitis) is one of the most commonly diagnosed conditions affecting the equine lung (Dixon et al., 1995; Franchini et al., 1998). This syndrome is considered to be caused by the interaction of environmental and genetic factors and is characterized by airway obstruction and alveolar neutrophil infiltration (Robinson, 1997; Laurent, 2002). Neutrophils degrade inhaled particles present in the airways by releasing protease-like elastases, peroxidases and nucleases. These proteolytic enzymes can destroy airway tissues directly by oxidation or indirectly by activating other proteases and/or inactivating protease inhibitors (PI). Cell damage is normally prevented by the action of protease inhibitors such as alpha-1-antitrypsin (AAT), which control the protease/antiprotease balance by inhibition of neutrophil elastase (Dallegri et al., 1995). In human COPD, low levels of serum PI caused by autosomal recessive mutations lead to tissue injury at sites of neutrophilic inflammation and ultimately to the development of pulmonary emphysema (Brantly et al., 1988, Selby et al., 1991, Cavarra et al.,

Send correspondence to Karin E. Brass. Universidade Federal de Santa Maria, Centro de Ciências Rurais, Departamento de Clínica de Grandes Animais, Laboratório de Imunogenética, Av. Roraima s/n, Camobi, 97105-900 Santa Maria, Rio Grande do Sul, Brazil. E-mail: kbrass@smail.ufsm.br. *Funding was provided by ConseIho Nacional de Desenvolvimento Científico e Tecnológico (CNPq).
1996). The equine protease inhibitor system is considered to be equivalent to the human protease inhibitor but protease inhibitor deficiency has never been reported in equine COPD. The equine PI system is composed of four closely-linked serine proteinase inhibitor genes (Spi 1-4) which have been cytogenetically assigned to chromosome ECA 24q15-16 (Lear et al., 1999). Twenty-two equine protease inhibitor alleles have been characterized (Braend, 1970; Juneja et al., 1978; Trommershausen-Smith and Suzuki, 1978) and eight (F, G, I, L, N, S, T and U) are commonly observed in thoroughbred horses. The high degree of protein polymorphism and heterozygosity is the result of the co-expression of the four Spi genes (Patterson et al., 1991; Dagleish et al., 1998).

In our study we evaluated the potential use of the equine protease inhibitor system as a possible marker for diagnosing COPD in horses. PI allele and genotype frequencies were compared between thoroughbred horses with COPD, inflammatory airway disease (IAD) and healthy (control) horses. These horses were examined during the first semester of 2002 for respiratory diseases at 3 different Brazilian racetracks (Tarumã in Curitiba, Paraná state; Cidade Jardim in São Paulo, São Paulo state; and Passo da Areia in Santa Maria, Rio Grande do Sul state) and at different breeding farms located in these areas. The diagnosis of COPD $(n=24)$, IAD $(n=38)$ and identification of healthy horses $(n=13)$ was based on clinical signs, cytology of bronchoalveolar lavage fluid and intrapleural pres- 
sure testing with a Ventigraph (Vinocur et al., 2004; supplier: Boehringer Ingelheim do Brasil, Divisão Vetmédica, São Paulo, Brazil). Serum samples were used for protease inhibitor typing which was performed using starch and polyacrylamide gel electrophoresis according to previously published protocols (Juneja et al., 1978; Braend, 1970; Trommershausen-Smith and Suzuki, 1978). Protease inhibitor typing from 3,600 horses registered at the Brazilian Thoroughbred Stud Book (THBI) (132 stallions, 384 dams and 3,084 horses born between 1998 and 2001) were included as a $4^{\text {th }}$ group in the genetic analyses, to estimate the overall PI allele frequency of the Brazilian thoroughbred population. Data from horses in the COPD, IAD and healthy groups were not included in the THBI group. PI allelic and genotypic frequencies of the 4 horse groups were estimated using the Genepop program (Raymond and Rosset, 1995), version 2001. Allele frequencies were used to estimate Hardy-Weinberg equilibrium, coefficient of inbreeding (Fis), genetic distance between groups (Fst) and to construct a dendrogram using the unweighted pair group method with averages (UPGMA) (Statistic Program, version 6; StatSoft Inc., 2300 east $14^{\text {th }}$ street, Tulsa, OK 74.104, USA). The five-generation pedigree of each COPD, AID and healthy horse was used to estimate inbreeding coefficients using the Pedigree Viewer program version 5.1 (Genetic Information Systems, University of New England, Australia). The heterogeneity test was applied to compare genotypic frequencies between COPD, IAD, healthy horse groups and THBI data.

We observed seven protease inhibitor alleles (G, I, L, $\mathrm{N}, \mathrm{S}, \mathrm{T}$ and $\mathrm{U}$ ) in the COPD, IAD and healthy horses and two additional alleles in the THBI data ( $\mathrm{F}$ and $\mathrm{L}_{2}$, Table 1). The inbreeding coefficients estimated using the pedigree data for each of the COPD, IAD and healthy horses ranged between 0.0005 and 0.078 for 18 horses, while a total of 57 horses had an estimated inbreeding coefficient of 0.00 (Figure 1C, D). Fisher's inbreeding coefficient (Fis) estimated using the protease inhibitor allele frequency data for each group and the 4 groups pooled was not significant (Fis Total $_{\text {T. }}$ $\chi^{2}: 6.12$, df: 8 , prob: 0.72 ). Genotypic similarity between and among the four groups was assessed by the heterogeneity test $\left(\chi_{\text {HeTEROGENEITY }}^{2}=95.24\right.$; df: 44$)$. The observed estimates of genetic distances between groups showed that the COPD group was separated from the IAD group by Fst $=0.0097$ and both were equidistant from the healthy horse group by Fst $=0.0116$. Genotype distribution and a tree diagram using allelic frequencies from the 4 groups are shown in Figures 1A and 1B.

It has been shown that human COPD is a result of protease inhibitor dysfunction and it can be inherited and/or acquired (i.e., cigarette-induced) (Gadek, 1988). In horses, the hereditary basis of COPD has only been postulated as one of the predisposing factors (Marti et al., 1991). As stated above, during the research published in our present paper we investigated the possible involvement of the equine protease inhibitor system in the onset of equine COPD (analogous to the hereditary protease inhibitor dysproteinaemia observed in humans) as previously proposed by Matthews (1979) who used acid polyacrylamide gel electrophoresis to estimate protease inhibitor allele frequencies in a mixed-breed equine population however, this author found no evidence of an association between a specific allele in the equine protease inhibitor system and the onset of COPD. In our study some of the variables used by Matthews (1979) were eliminated because we only used thoroughbred horses diagnosed with COPD, IAD and healthy horses (based on physical examination and comple-

Table 1 - Proteinase inhibitor (PI) allele frequencies in thoroughbred horses.

\begin{tabular}{|c|c|c|c|c|c|c|c|}
\hline \multirow[b]{2}{*}{ Alleles } & \multicolumn{3}{|c|}{ Thoroughbreds (present study) } & \multicolumn{4}{|c|}{ Data from other studies (thoroughbreds and non-thoroughbreds) } \\
\hline & $\begin{array}{l}\text { COPD } \\
(n=24)\end{array}$ & $\begin{array}{c}\text { IAD } \\
(n=38)\end{array}$ & $\begin{array}{l}\text { Healthy } \\
(\mathrm{n}=13)\end{array}$ & $\begin{array}{c}\text { THBI } \\
(\mathrm{n}=3,600)\end{array}$ & $\begin{array}{c}\text { THBII } \\
(\mathrm{n}=14,517)\end{array}$ & $\begin{array}{l}\text { THBIII } \\
(n=63)\end{array}$ & $\begin{array}{l}\text { COPDIII } \\
(\mathrm{n}=52)\end{array}$ \\
\hline $\mathrm{F}$ & - & - & - & 0.03 & 0.030 & 0.063 & 0.096 \\
\hline G & 0.04 & 0.01 & 0.08 & 0.01 & 0.015 & - & - \\
\hline I & 0.06 & 0.07 & 0.04 & 0.04 & 0.060 & 0.040 & 0.019 \\
\hline L2 & - & - & - & 0.01 & - & - & \\
\hline $\mathrm{L}$ & 0.46 & 0.42 & 0.50 & 0.44 & 0.450 & 0.539 & 0.317 \\
\hline $\mathrm{N}$ & 0.25 & 0.33 & 0.15 & 0.29 & 0.185 & 0.048 & 0.048 \\
\hline $\mathrm{S}$ & 0.02 & 0.03 & 0.11 & 0.02 & 0.130 & 0.150 & 0.115 \\
\hline $\mathrm{T}$ & 0.04 & 0.04 & 0.04 & 0.05 & - & - & - \\
\hline $\mathrm{U}$ & 0.13 & 0.10 & 0.08 & 0.11 & 0.130 & 0.151 & 0.211 \\
\hline Others & - & - & - & - & 0.001 & - & 0.192 \\
\hline
\end{tabular}

Key: chronic obstructive pulmonary disease (COPD); inflammatory airway disease (IAD); healthy control horses (Healthy); a population of 3,600 thoroughbreds (132 stallions, 384 dams and 3,084 horses born between 1998 and 2001) from the Brazilian Thoroughbred Stud Book (THBI); thoroughbreds typed by Bowling \& Clark (1985) (THBII); thoroughbreds used as controls (THBIII); and mixed-breed horses with COPD typed by Matthews (1979) (COPDIII). 
(A)

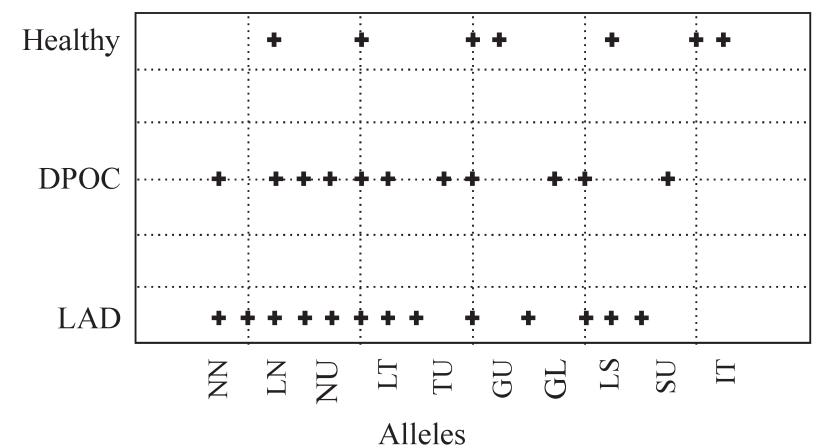

(C)

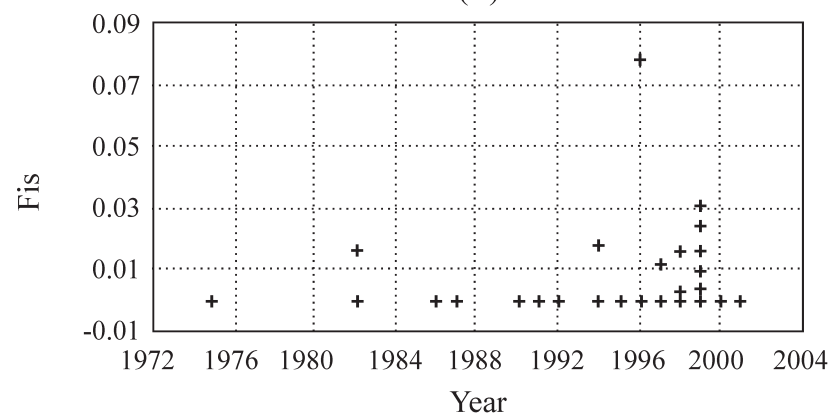

(B)

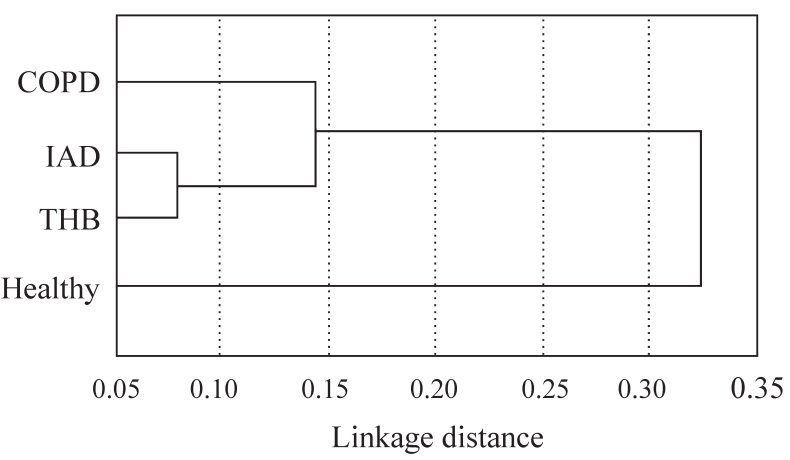

(D)

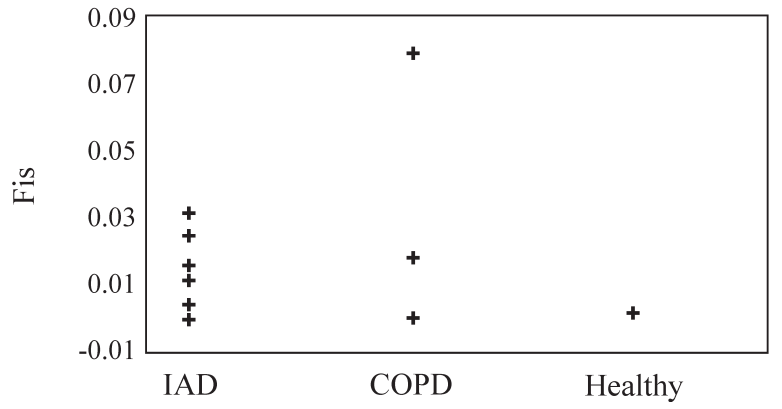

Figure 1 - (A) PI genotype distribution in thoroughbreds with chronic obstructive pulmonary disease (COPD), inflammatory airway disease (IAD) and healthy control horses (Healthy). (B) Tree diagram using PI allelic frequencies of horses with COPD, IAD, Healthy and a population of 3,600 thoroughbreds (THBI). (C) Year of birth and inbreeding coefficient (Fis) of the 75 thoroughbred horses with COPD, IAD and healthy horses used in this study. (D) Fis of 75 thoroughbred horses with COPD, IAD and healthy horses.

mentary diagnostic methods). In addition, we also used starch and alkaline polyacrylamide gel electrophoresis for the protease inhibitor typing, a methodology that can detect all 22 alleles previously characterized for the equine protease inhibitor system (Braend, 1970; Juneja et al., 1978; Trommershausen-Smith and Suzuki, 1978). The seven alleles (G, I, L, N, S, T and U) identified by us in the COPD, $\mathrm{IAD}$ and healthy horses, and the two low frequency alleles $\left(\mathrm{F}=0.03 ; \mathrm{L}_{2}=0.01\right)$ in the THBI population (Table1) showed similar frequencies to those observed in thoroughbred horses typed in the United States of America by Bowling and Clark (1985). Matthews (1979) reported the presence of only six alleles in thoroughbred horses, but this may have been due to the fact that this author studied closely related animals. To avoid genealogical influence in our genetic analysis we estimated inbreeding coefficients using the pedigree data of each COPD, IAD and healthy horse along with the protease inhibitor Fis values of the four groups of horses (Figure 1 C, D). In spite of this, the heterogeneity test showed genotypic similarity between the COPD, IAD, healthy groups and the population of 3,600 thoroughbred horses and no allele or genotype variants observed in this study were found to be associated with the onset of equine COPD.

In humans, the conventional approach for protease inhibitor allele typing uses a combination of polyacrylamide gel isoelectric focusing of serum at $\mathrm{pH} 4$ to 5 and estimation of seric protease inhibitor levels using Radio Immuno Assays (RIA) and family studies (Wewers et al., 1987). In horses, the typing of the protease inhibitor system is more complex. Identification of Spi variants using electrophoresis and the measurements of serum Spi concentration by ELISA are not considered ideal procedures (Dagleish et al., 1999, 2000), and the molecular sequence of each Spi has still not been fully determined. It therefore appears that there is a need to establish more efficient methods to identify the genetic variants derived from each Spi (Godard et al., 1998; Milenkovic et al., 2002) in order to clarify the role of this locus in the onset of equine COPD.

\section{References}

Braend M (1970) Genetic of horse acidic prealbumins. Genetics 65:495-503.

Brantly M, Nukiwa Y and Crystal RG (1988) Molecular basis of alpha1-antitrypsin deficiency. Am J Med 84:13-31.

Bowling AT and Clark RS (1985) Blood group and protein polymorphism gene frequencies for seven breeds of horses in the United States. Animal Blood Groups Biochem Genet 16:93-108.

Cavarra E, Martorana PA, Gambelli F, de Santi M, van Even P and Lungarella G (1996) Neutrophil recruitment into the lungs is associated with increased lung elastase burden, de- 
creased lung elastin, and emphysema in alpha 1 proteinase inhibitor-deficient mice. Lab Invest 75:273-280.

Dagleish MP, Pemberton AD, Brazil TJ, McAleese SM, Miller HR and Scudamore CL (1999) Kinetics of equine neutrophil elastase release and superoxide anion generation following secretagogue activation: A potential mechanism for antiproteinase inactivation. Vet Immunol Immunopathol 72:257-275.

Dagleish MP, De Jaham C, Suprenan S and Scudamore CL (2000) Serum alpha-1-proteinase inhibitor concentration in 2 Quarter Horse foals with idiopathic pyogranulomatous panniculitis. Equine Vet J 32:449-452.

Dallegri F, Ottonello L and Bevilacqua M (1995) Possible modes of action of nimesulide in controlling neutrophilic inflammation. Drug Res 45:1114-1117.

Dixon, PM, Railton DI and McGorum BC (1995) Equine pulmonary disease: A case control study of 300 referred cases. Part 1: Examination techniques, diagnostic criteria and diagnosis. Equine Vet J 27:416-421.

Franchini M, Gilli U, Akens MK, Fellenberg RV and Bracher V (1998) The role of neutrophil chemotactic cytokines in the pathogenesis of equine chronic obstructive pulmonary disease (DPOC). Vet Immunol Immunopathol 66:53-64.

Gadek J (1988) Introduction. Am J Med 84(suppl 6A):1-2.

Godard S, Schibler L, Oustry A, Cribiu EP and Guerin G (1998) Construction of a horse BAC library and cytogenetical assignment of 20 type I and type II markers. Mamm Genome 9:633-637.

Juneja R K, Ghane B and Sandberg K (1978) Genetic polymorphism of the vitamin D binding protein and another postalbumin protein in horse serum. Anim Blood Groups Biochem Genetics 9:29-36.

Laurent LC (2002) IDA: Cough, poor performance, mucus in the airways - What is so important about that? Proc Am Ass Equine Pract 48:200-209.

Lear TL, Brandon R, Masel A, Bell K and Bailey E (1999) Horse alpha-1-antitrypsin, beta-lactoglobulins 1 and 2, and transferrin map to positions 24q15-q16, 28q18-qter, 28q18-qter and 16q23, respectively. Chromosome Res 7:667.
Marti E, Gerber H, Essich G, Oulehla J and Lazary S (1991) The genetic basis of equine allergic diseases 1 . Chronic hypersensitivity bronchitis. Equine Vet J 23:457-460.

Matthews AG (1979) Identification and characterisation of the major antiproteases in equine serum and an investigation of their role in the onset of chronic obstructive pulmonary disease (COPD). Equine Vet J 11:177-182.

Milenkovic D, Oustry-Vaiman A, Lear TL, Billault A, Mariat D, Piumi F, Schibler L, Cribiu E and Guerin G (2002) Cytogenetic localization of 136 genes in the horse: Comparative mapping with the human genome. Mamm Genome 13:524-534.

Patterson SD, Bell K and Shaw DC (1991) The equine major plasma serpin multigene family: Partial characterization including sequence of the reactive-site regions. Biochem Genet 29:477-499.

Raymond M and Rousset F (1995) Population genetics software for exact test and ecumenicism. Genepop (version 1.2). J Heredity 86:248-249.

Robinson NE (1997) Pathogenesis and management of airway disease. Proc Am Ass Equine Pract 43:106-115.

Selby C, Drost E, Lannan S, Wraith PK and MacNee W (1991) Neutrophil retention in the lungs of patients with chronic obstructive pulmonary disease. Am Rev Respir Dis 143:13591364.

Trommershausen-Smith A and Suzuki Y (1978) Identity of XK and $\mathrm{Pa}$ systems in equine serum. Animal Blood Groups Biochem Genet 9:127-128.

Vinocur ME, Brass KE, Caetano AR, Michelloto PV and Silva CAM, Bronchoalveolar lavage cytology and ventigraphy as an aid in the diagnosis of pulmonary disease in thoroughbred horses in Brazil. Brazilian Journal of Veterinary Research and Animal Science, submitted in 2004.

Wewers MD, Casolaro MA, Sellers SE, Swayze SC, McPhaul KM, Wittes JT and Crystal RG (1987) Replacement therapy for alpha $a_{1}$-antitrypsin deficiency associated with enphysema. N Engl J Med 136:1055-1062.

Associate Editor: Pedro Franklin Barbosa 